\title{
SUAP Instant Messaging: aplicativo institucional de mensagens instantâneas
}

\author{
Matuzael dos Santos Dias', Bernardo Vilela Gonçalves' ${ }^{1}$, Leo Moreira Silva' ${ }^{1}$, José \\ Durval Pacheco Tavares Junior ${ }^{1}$
}

Instituto Federal da Educação, Ciência e Tecnologia do Rio Grande do Norte (IFRN)

Caixa Postal 59580-000 - Ceará-Mirim - RN - Brasil

matuzaeldias@hotmail.com, vilelabernardo9014@gmail.com, \{leo.silva, durval.pacheco\} @ifrn.edu.br

\begin{abstract}
The use of digital ways for education is a reality in various institutions around the world. Platforms such as Google Classroom, Edmodo, and even WhatsApp, offer services of virtual groups where it is possible to share files and messages. However, although the practicality and usability, this last one may come to fail, once not all the information in the app is about school. From this, this work proposes the development of a mobile app of instant messaging addressed exclusively to the educational environment, which allows the effective and instantaneous transaction of text messages and digital files only in the institutional setting.
\end{abstract}

Resumo. O uso dos meios digitais para educação é uma realidade em inúmeras instituições pelo mundo. Plataformas como Google Sala de Aula, Edmodo e até mesmo o WhatsApp, oferecem serviços de grupos virtuais onde é possível compartilhar arquivos e realizar trocas de mensagens. No entanto, apesar da praticidade e usabilidade, este último pode vir falhar, uma vez que nem toda informação presente no aplicativo se resume à escola. A partir disso, o presente trabalho propõe o desenvolvimento de um aplicativo móvel de trocas de mensagens instantâneas exclusivamente voltado para o ambiente educacional, que permita a transação prática e instantânea de mensagens de texto e de arquivos digitais apenas no meio institucional.

\section{Introdução}

A tecnologia digital se molda para atender determinadas necessidades humanas e oferecer soluções práticas e simples. Com a educação não é diferente, uma vez que o Mobile Learning é uma realidade em diversas instituições ao redor do mundo.

Conforme uma pesquisa realizada em 2016 pelo Centro de Estudos sobre as Tecnologias da Informação e Comunicação - Cetic, 52\% das instituições educacionais brasileiras utilizam aparelhos celulares nas atividades escolares, número que ascende ao longo dos anos [TIC Educação 2016]. É importante destacar que essa nova modalidade de ensino, conhecida também como ensino híbrido, promove bons resultados por permitir a construção do conhecimento em rede, já que dispõe de inúmeras ferramentas que se adequam às necessidades individuais dos alunos e professores [Pereira 2016]. 
VII Congresso Brasileiro de Informática na Educação (CBIE 2018)

Anais do XXIX Simpósio Brasileiro de Informática na Educação (SBIE 2018)

Dessa forma, o processo de ensino deixa de ser centrado no docente e passa a ser construído em conjunto, uma vez que os próprios alunos também se fazem protagonistas, proporcionando maior interesse e curiosidade na realização das atividades propostas [Pereira 2016].

Os Ambientes Virtuais de Aprendizagem (AVA), embora sejam ferramentas educacionais, não atendem à todas as demandas dos professores e alunos do Instituto Federal de Educação, Ciência e Tecnologia do Rio Grande do Norte (IFRN). Outras ferramentas, como o WhatsApp, de comunicação instantânea, não são exclusivamente educacionais e, portanto, podem trazer problemas quando usados para esse fim.

Diante disso, este trabalho propõe o desenvolvimento de um aplicativo mobile, intitulado de SUAP-IM (SUAP Instant Messaging), com funcionalidades semelhantes aos supracitados, porém, com fins educacionais e integrado ao ambiente institucional (Sistema Unificado de Administração Pública - SUAP) ao qual será aplicado, o IFRN. Muitas de suas funcionalidades serão baseadas em estudos sobre funções relevantes dos aplicativos supracitados. Por outro lado, haverá, também, serviços específicos que serão fornecidos a partir da integração com o ambiente institucional.

O aplicativo tem por objetivo cessar com problemas vigentes quanto ao uso de determinados ambientes no modelo Mobile Learning, como, por exemplo, privacidade e identificação. Nesse sentido, apenas informações relativas a instituição e a educação serão tratadas, o que o torna exclusivamente vinculado ao Instituto Federal, garantindo melhor qualidade dessas informações e menos possibilidades de distração por parte dos alunos.

\section{Trabalhos Relacionados}

As plataformas AVA atendem às necessidades de comunicação e de ensino entre professores e alunos, permitindo a criação de fóruns, envio de atividades, compartilhamento de documentos, vídeos e imagens. É necessário um computador ou até mesmo um celular com acesso à internet para ter acesso a esses dados em qualquer lugar [Pereira 2016]. Exemplos dessas ferramentas são o Edmodo e o Google Sala de Aula.

Tais ferramentas, no entanto, não dispõem de um layout prático e a comunicação instantânea nem sempre é garantida, o que muitas vezes leva os alunos terem de aguardar por horas para que uma dúvida seja esclarecida. Além disso, é preciso possuir um acesso razoável a internet e um dispositivo com poder de processamento regular no caso de smartphones, para que o conteúdo seja acessado com praticidade e agilidade [Oliveira et al. 2014].

Outro aplicativo que é bastante utilizado com esse intuito é o WhatsApp. Mesmo que não possua fins exclusivamente educacionais, o software pode ser de grande valia para o aprendizado, especialmente pela interatividade que proporciona. Essa ferramenta, no entanto, apresenta empecilhos que dificultam sua integração com o ambiente escolar. Por não ser exclusivamente educacional, o estudante se encontra suscetível a distrações durante o uso. Notificações não relacionadas a atividades educacionais, falta de privacidade, pelo fato de ter que ceder o número de telefone aos interessados, e problemas de identificação, por não haver a garantia de que os envolvidos se conheçam, são alguns desses problemas [Suarez 2017].

Este trabalho se difere por ser uma proposta de aplicativo móvel de comunicação instantânea totalmente atrelado ao ambiente institucional ao qual será aplicado, o IFRN. 
VII Congresso Brasileiro de Informática na Educação (CBIE 2018)

Anais do XXIX Simpósio Brasileiro de Informática na Educação (SBIE 2018)

Por haver essa vinculação, apenas professores e alunos regularmente matriculados poderão ter acesso. Assim, problemas como privacidade e identificação serão sanados, pois dispensa a necessidade de trocas de números de telefone entre as partes e os envolvidos terão os seus dados relevantes para o contexto do aplicativo extraídos do ambiente institucional.

\section{Tecnologia, Educação e Comunicação}

A tríade comunicação, educação e novas tecnologias resume uma das problemáticas substantivas do novo milênio. Nas últimas décadas a sociedade contemporânea absorveu as TICs em todos os seus segmentos. O motivo para essa disposição está na percepção de que as tecnologias digitais trazem conforto, vantagens competitivas e podem ser obtidas mais facilmente devido à redução dos custos [Junior 2012].

Documentos oficiais como os Parâmetros Curriculares Nacionais (PCNs e PCNEM) recomendam o uso das tecnologias da informação e comunicação (TIC). O documento diz que "é indiscutível a necessidade crescente do uso de computadores pelos alunos como instrumento de aprendizagem escolar, para que possam estar atualizados em relação às novas tecnologias da informação e se instrumentalizarem para as demandas sociais presentes e futuras" [Brasil 1998]. Ainda, "As tecnologias da comunicação e da informação e seu estudo devem permear o currículo e suas disciplinas” [Brasil 1999].

Quando utilizadas com fins devidos, as TICs são grandes aliadas da educação. Garantem conexão entre alunos e professores, permitindo que o educador transmita o conhecimento com mais eficiência [Oliveira e Moura 2015].

A utilização de smartphones pelos alunos do IFRN ocorre com frequência, permitindo ao aplicativo proposto realizar uma integração direta entre a tecnologia e o âmbito educacional através da comunicação instantânea. Dessa forma, será possível compartilhar conhecimentos e informações de maneira virtual entre seus usuários, viabilizando que processos educacionais ocorram de maneira mais fluida e intuitiva.

\section{SUAP-IM: construção e funcionamento}

O aplicativo está sendo desenvolvido com a linguagem JavaScript [JavaScript 2018] e o framework React Native [React Native 2018], sendo compilado para a plataforma Android, inicialmente, e em um ambiente institucional. Para que se caracterize como tal e atinja o seu objetivo, foi implementado uma integração com a plataforma usada pela Instituição, o SUAP. Dessa forma, apenas professores e alunos regularmente matriculados poderão ter acesso ao aplicativo.

Como principais características, o aplicativo fornecerá funcionalidades como troca de mensagens instantâneas e envio de mídias, compartilhamento de informações entre alunos e professores, criação automática de grupos baseados nas turmas dos docentes e discentes, anúncios e avisos. Ainda, para o aluno, será possível verificar os principais prazos, por prioridade, a serem cumpridos para as disciplinas matriculadas e ter acesso ao calendário de atividades registrado pelos professores dessas disciplinas.

Com a integração ao ambiente institucional, o aplicativo mantém a privacidade dos envolvidos, uma vez que não é necessário número de telefone, e-mail ou cadastro para usá-lo. Para isso, o usuário deve possuir vínculo regular para que seus dados como nome, turma e matrícula, sejam resgatados do banco de dados do IFRN de modo que 
VII Congresso Brasileiro de Informática na Educação (CBIE 2018)

Anais do XXIX Simpósio Brasileiro de Informática na Educação (SBIE 2018)

sejam utilizados para a execução de funcionalidades e exibição de informações. Sendo assim, os usuários estarão devidamente identificados a partir da integração com o SUAP.

Além disso, diferentemente do WhatsApp, o acesso a API do SUAP permitirá que os grupos de conversas, cada um deles formados pelo professor e os alunos que estão contidos na disciplina correspondente, sejam gerados automaticamente de modo que o acesso de terceiros se torna indisponível. A comunicação é feita apenas por grupo, não havendo chats individuais.

A Figura 1 a seguir mostra os primeiros protótipos já criados do aplicativo, que contam com algumas funcionalidades ainda a serem desenvolvidas, como as trocas de mensagens e anexo de arquivos. Na Figura 1-A, uma vez feito o login, o aluno pode visualizar um grupo para cada uma das disciplinas as quais está matriculado. Quando um clique é feito em algum desses grupos, o aluno é direcionado para a tela mostrada na Figura 1-B. Essa tela representa o ambiente de chat relacionado àquela disciplina. Nela, é possível comunicar-se e compartilhar arquivos de mídia com os alunos que também estão matriculados, além do professor da disciplina.

A Figura 1-C exibe todas as atividades, avaliações e aulas ainda não concluídas propostas para o aluno. Cada bloco contêm a disciplina a que se refere, a data que acontecerá (ou data limite de entrega de uma atividade) e uma barra indicativa colorida. Cada cor dessa barra reflete a proximidade com a data final, onde: a vermelha indica que essa data está muito próxima; já a amarela indica que o prazo ainda está razoável; por fim, a cor verde mostra que a atividade referida ainda está distante do prazo final.
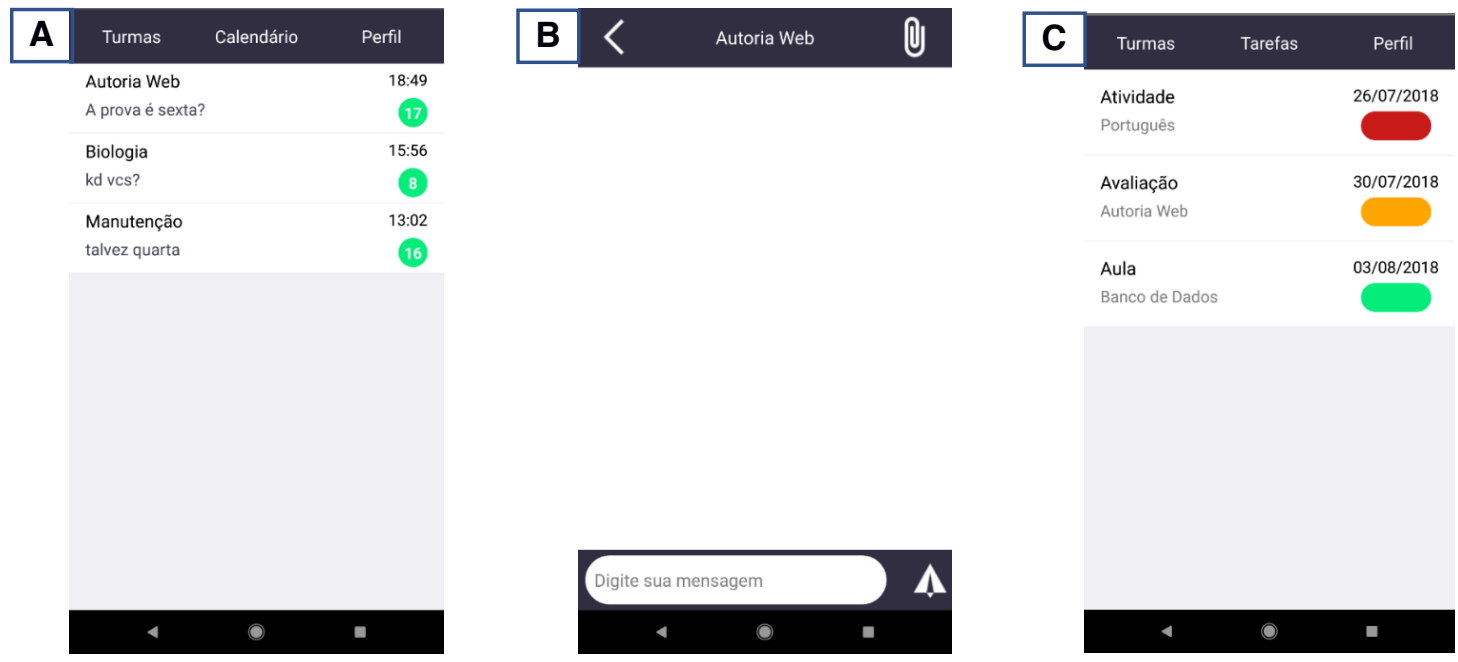

Figura 1. Protótipo de algumas telas do aplicativo proposto

\section{Considerações finais}

Uma vez que o uso das TICs está presente nas mais diversas atividades e setores da sociedade, a correta utilização na educação pode ser de grande valia. Considerando a popularização dos smartphones e a sua inevitável utilização por alunos e professores, utilizar esse dispositivo como aliado ao processo educacional é de suma importância.

A partir do desenvolvimento e utilização dessa aplicação, espera-se que haja relevantes benefícios aos alunos e professores do IFRN quanto ao processo de aprendizagem e que problemas de comunicação e privacidade, que antes existiam em 
VII Congresso Brasileiro de Informática na Educação (CBIE 2018)

Anais do XXIX Simpósio Brasileiro de Informática na Educação (SBIE 2018)

outras plataformas, sejam solucionados ou controladamente contornados. Com essa solução, além da principal funcionalidade de comunicação instantânea com membros das disciplinas as quais está matriculado e seus respectivos professores, o aluno terá, na palma de suas mãos, informações relevantes do ambiente institucional, como o calendário com todas as datas limite de atividades, avaliações e aulas.

\section{Trabalhos futuros}

Como trabalhos futuros, pretende-se integrar mais serviços do SUAP, como calendário, acesso às frequências e o boletim. Dessa forma, o aplicativo além de atingir o seu objetivo principal de mensagens instantâneas entre discentes e professores, pode agregar valor com funcionalidades secundárias como as mencionadas.

A partir da consolidação do aplicativo, o IFRN pode adotá-lo e oficializá-lo institucionalmente, podendo ser adotado pelos diversos docentes e discentes distribuídos em todos os campi. Além disso, o aplicativo pode ser exportado para outros Institutos Federais, desde que utilizem o SUAP para o gerenciamento de atividades acadêmicas.

\section{Referências}

Brasil (1998). "Parâmetros curriculares nacionais: terceiro e quarto ciclos do ensino fundamental: introdução aos parâmetros curriculares nacionais". Brasília: MEC/SEF.

Brasil (1999). "Parâmetros Curriculares Nacionais: Ensino Médio". Brasília: Ministério da Educação.

JavaScript. (2018) "Ready to try JavaScript?”, https://www.javascript.com, Agosto.

Junior, W. T. L. (2012). "Big Data, Jornalismo Computacional e Data Journalism: estrutura, pensamento e prática profissional na Web de dados". Estudos em Comunicação, 12, 207-222.

Oliveira, E. D. S., Medeiros, H., Leite, J. E. R., Anjos, E. G., \& Oliveira, F. S. (2014). "Proposta de um modelo de cursos baseado em mobile learning: um experimento com professores e tutores no whatsapp". In Anais do XI Congresso Brasileiro de Ensino Superior a Distância. Florianópolis/SC (pp.05-08).

Pereira, I. D. S. D. (2016). “Uma experiência de Ensino Híbrido utilizando a plataforma Google sala de aula". In SIED: EnPED-Simpósio Internacional de Educação a Distância e Encontro de Pesquisadores em Educação a Distância.

React Native. (2018) “A framework for building native apps using React", https://facebook.github.io/react-native/, Agosto.

Suarez, J. (2017) "As vantagens e as desvantagens do modelo de ensino sala de aula invertida", http://www.otempo.com.br/cidades/grupos-de-whatsapp-motivam-77-dosproblemas-nas-escolas-1.1530823, Agosto.

TIC Educação. (2016) "Pesquisa Sobre o Uso das Tecnologias de Informação e Comunicação nas Escolas Brasileiras", https://cetic.br/media/docs/publicacoes/2/TIC_Edu_2015_LIVRO_ELETRONICO.p df, Agosto. 